\title{
El equilibrio económico en los contratos administrativos
}

The economic balance in administrative contracts

LIBARDO RODRÍGUEZ RODRÍGUEZ*

Resumen: El estudio aborda el principio del equilibrio económico en los contratos administrativos como principio específico de esa clase de contratos, tanto en el Derecho comparado como en Derecho colombiano. Para el efecto, se precisa el concepto y se analizan los antecedentes históricos y el origen de la figura, la justificación de la existencia del principio, las condiciones generales para la procedencia de su aplicación, los instrumentos jurídicos existentes para su efectividad y las causales específicas que dan lugar a la ruptura del equilibrio económico.

Palabras clave: Contratos administrativos - equilibrio económico - equilibrio financiero - ecuación contractual

Abstract: This article studies the economic balance principle in the administrative contracts, as a specific principle of this kind of contracts in comparative law and in Colombian law. For this purpose, the concept will be specified and the historical precedents and the origin of the figure will be analyzed, the justification of the existence of the principle, the general conditions that allow its application, the juridical instruments available for its claim, and the specific grounds that permit the breach of the economic balance.

Key words: Administrative contracts - economic balance - financial balance contractual equation

CONTENIDO: INTRODUCCIÓN.- I. EL CONTENIDO DEL PRINCIPIO DEL EQUILIBRIO ECONÓMICO EN LOS CONTRATOS ADMINISTRATIVOS.- II. ANTECEDENTES Y ORIGEN DEL EQUILIBRIO ECONÓMICO EN LOS CONTRATOS ADMINISTRATIVOS.- III. JUSTIFICACIÓN DE LA EXISTENCIA DEL PRINCIPIO DEL EQUILIBRIO ECONÓMICO EN LOS CONTRATOS ADMINISTRATIVOS.IV. CONDICIONES GENERALES PARA LA PROCEDENCIA DE LA APLICACIÓN DEL PRINCIPIO DEL EQUILIBRIO ECONÓMICO EN LOS CONTRATOS ADMINISTRATIVOS.- V. INSTRUMENTOS JURÍDICOS PARA HACER EFECTIVO EL DERECHO AL RESTABLECIMIENTO DEL EQUILIBRIO ECONÓMICO DEL CONTRATO.VI. CAUSALES ESPECÍFICAS QUE DAN LUGAR A LA RUPTURA DEL EQUILIBRIO ECONÓMICO EN LOS CONTRATOS ADMINISTRATIVOS.- VII. CONCLUSIONES.

* Es profesor de Derecho Administrativo y ex consejero del Estado de Colombia. Asimismo, es miembro de las asociaciones Iberoamericana e Internacional de Derecho Administrativo, del Foro Iberoamericano de Derecho Administrativo y de la Academia Internacional de Derecho Comparado. 


\section{INTRODUCCIÓN}

El estudio del régimen de los contratos administrativos suele dividirse, debido a la doctrina, en varias partes, y de acuerdo con las diversas etapas que se presentan en la actividad contractual: la etapa precontractual o de formación del contrato, la etapa contractual o de ejecución del mismo y la de terminación o finalización del contrato ${ }^{1}$. La etapa contractual o de ejecución del contrato administrativo se identifica por el período de tiempo durante el cual los cocontratantes deben ejecutar las prestaciones estipuladas, y comprende del perfeccionamiento a su finalización, independientemente del motivo determinante de esta. Es precisamente en esta etapa en la cual se ubica el tema del equilibrio económico en los contratos administrativos.

En efecto, según una clasificación doctrinal clásica, esta etapa contractual o de ejecución del contrato administrativo se encuentra regida por diversos criterios o nociones dominantes, todos ellos interrelacionados entre sí. Entre esos criterios o nociones pueden citarse los siguientes: (a) la común intención de las partes; (b) el servicio público que involucra la ejecución de un contrato administrativo; (c) el carácter de colaborador que tiene el contratista de la administración; (d) las prerrogativas de Derecho público y las relaciones entre el poder público y el contrato; (e) el cambio de circunstancias y la mutabilidad del contrato administrativo; y (f) el equilibrio económico y financiero del contrato, como expresión de la obligación de mantener una "equivalencia honesta" en las prestaciones ${ }^{2}$.

La última de las citadas nociones dominantes en la ejecución del contrato — - esto es, la del equilibrio económico y financiero- hace relación a que durante la ejecución del contrato debe mantenerse una equivalencia o correspondencia entre las prestaciones que deben cumplir los cocontratantes. En ese orden de ideas, si tal correspondencia se rompe o resulta alterada, puede nacer el derecho para la parte afectada de que su cocontratante tome las medidas necesarias para restablecer el equilibrio. No obstante, no toda alteración en las condiciones contractuales genera el deber para una de las partes de restablecer el equilibrio económico del contrato, pues se requiere, además, que tal alteración reúna unas determinadas características específicas, las cuales serán objeto de análisis detenido en este escrito.

Sin embargo, para entender la razón de ser y la realidad que se encuentran detrás de la aplicación de este principio que domina la ejecución de

1 Esta estructura metodológica para el estudio de los contratos administrativos es aplicada, entre otros libros, en Rivero, Jean y Jean Waline. Droit administratif. Décimo séptima edición. París: Dalloz, 1998, pp. 123 y siguientes, y en Escola, Héctor Jorge. Tratado integral de los contratos administrativos. Tomo I. Buenos Aires: Editorial Depalma, 1977.

2 Véase De Laubadère, André, Franck Moderne y Pierre Delvolvé. Traité des contrats administratifs. Volumen I. Segunda edición. París: LGDJ, 1983, pp. 699 y siguientes. 
los contratos administrativos, también resulta indispensable presentar algunas reflexiones sobre su génesis, su permanencia y justificación en el Derecho administrativo contemporáneo, y los mecanismos o instrumentos jurídicos indispensables para su efectividad práctica.

En tal orden de ideas, para efectos metodológicos, analizaremos el principio del equilibrio económico en los contratos administrativos en seis partes: en primer lugar, precisaremos el contenido del principio (I); posteriormente, expondremos los antecedentes históricos y el origen de la figura (II); más adelante, estudiaremos las diversas teorías que han justificado la existencia de este principio (III); luego veremos las condiciones generales para la procedencia de su aplicación (IV) y explicaremos los instrumentos jurídicos que otorga el ordenamiento para la efectividad del principio (V); finalmente, enunciaremos las causales específicas que dan lugar a la ruptura del equilibrio económico del contrato (VI). Una vez realizada la presentación anterior, formularemos algunas conclusiones.

\section{EL CONTENIDO DEL PRINCIPIO DEL EQUILIBRIO ECONÓMICO EN LOS CONTRATOS ADMINISTRATIVOS}

Los contratos administrativos deben ser pactados de tal manera que exista una interdependencia entre las prestaciones; es decir, como contratos sinalagmáticos que son, debe existir una reciprocidad entre las obligaciones de cada una de las partes, de tal manera que exista una correspondencia de unas con otras, y se los pueda considerar como equivalentes las prestaciones pactadas. Entonces, en aplicación de esa idea, el principio del equilibrio contractual se refiere a la necesidad de que dicha correspondencia entre prestaciones —esto es, entre derechos y obligaciones - se mantenga hasta la finalización del contrato.

La doctrina especializada ha definido el principio del equilibrio económico del contrato en los siguientes términos: "el equilibrio financiero, o la ecuación financiera del contrato, es una relación establecida por las partes contratantes en el momento de celebrar el contrato, entre un conjunto de derechos del cocontratante y un conjunto de obligaciones de este, considerados equivalentes: de ahí el nombre de ecuación (equivalencia-igualdad)"3.

Otra definición que podemos encontrar en la doctrina tradicional es la siguiente:

Esta idea de equilibrio o, como se dice aún, de ecuación financiera del contrato, consiste en considerar el contrato administrativo como un

3 Marienhoff, Miguel S. "Contratos administrativos. Teoría general". En Tratado de Derecho administrativo. Tomo III-A. Cuarta edición. Buenos Aires: Abeledo Perrot, 1998, p. 469. En igual sentido, véase Escola, Héctor Jorge. Tratado integral de los contratos administrativos. Volumen I, p. 452. 
conjunto en el cual los intereses de las partes se condicionan; cuando, en algunas condiciones [...], el equilibrio inicialmente considerado se rompe en detrimento del particular cocontratante, este tiene derecho para que el equilibrio sea restablecido por la administración contratante en forma de una compensación pecuniaria ${ }^{4}$.

En relación con este tema, la jurisprudencia contencioso-administrativa colombiana ha dicho enfáticamente que "el contrato estatal debe entonces colmar las expectativas de uno y otro cocontratante, para lo cual se ha previsto la conservación de la ecuación financiera del contrato existente a la fecha en que surge la relación jurídico negocial"

Además, ha afirmado que, con el equilibrio contractual, "se pretende que la correspondencia existente entre las prestaciones correlativas que están a cargo de cada una de las partes del contrato, permanezca durante toda su vigencia, de tal manera que a la terminación de este, cada una de ellas alcance la finalidad esperada con el contrato".

Según la misma jurisprudencia, lo anterior implica que "cuando las condiciones económicas pactadas a la celebración del contrato, se alteran en perjuicio de una de las partes cocontratantes, a consecuencia de hechos que no le son imputables y que ocurren con posterioridad a la celebración del mismo, surge el deber de reparar la ecuación financiera del contrato"?.

De otra parte, una lectura atenta de todas las normas del estatuto colombiano de contratación de la administración pública, que citaremos en el punto II.2 de este escrito, permite concluir que el principio de ecuación contractual al que se refiere el artículo 27 de la ley 80 de 1993 es equivalente al equilibrio económico del contrato, pues no otra razón de ser tendría que las normas se refieran reiteradamente a la necesidad de ajustar precios y tomar otras medidas de tipo financiero o económico para conservar la equivalencia entre las prestaciones pactadas u ofrecidas. En otras palabras, la ecuación contractual debe ser correctamente entendida como equilibrio económico y financiero del contrato ${ }^{8}$.

En este sentido, vale la pena hacer notar que la jurisprudencia constitucional colombiana ha dicho que en el Derecho administrativo:

[...] es evidente que las prestaciones correlativas de las partes, en virtud del principio de la justicia conmutativa, tienen que mantener una

4 De Laubadère, André e Yves Gaudemet. Traité de droit administratif. Tomo I. Décimo sexta edición. París: LGDJ, 2001, p. 706.

5 Consejo de Estado, Sala de lo Contencioso Administrativo, sección tercera: sentencia del 26 de febrero de 2004, expediente 1991-07391 (14.043)

6 lbíd.

7 lbíd.

8 Véase Benavides, José Luis. El contrato estatal. Segunda edición, número 156. Bogotá: Universidad Externado de Colombia, 2004. 
equivalencia siguiendo el criterio objetivo de proporción o simetría en el costo económico de las prestaciones, lo que exige que el valor a recibir por el contratista, en razón de los bienes, obras o servicios que le entrega al Estado, deba corresponder al justo precio imperante en el mercado. Con ello, se fija un límite al ejercicio del principio de la autonomía de la voluntad, en aras de racionalizar la posición dominante de la administración, mantener el equilibrio del contrato y, de este modo, garantizar los derechos del contratista que se constituye en la parte débil de la relación contractual ${ }^{9}$ (mis subrayados).

Más adelante, la misma providencia aclara que:

[...] la reciprocidad en las prestaciones contractuales comporta un principio connatural o esencial al contrato administrativo que corresponde a la categoría de los sinalagmáticos (en virtud del principio del gasto público, los negocios jurídicos unilaterales y gratuitos no se integran al régimen común u ordinario de contratación estatal). Su aplicación en el campo del derecho público surge inicialmente de la jurisprudencia y de la doctrina, ante la apremiante necesidad de garantizar la estructura económica del contrato frente a las distintas variables que podrían afectar su cumplimiento y ejecución material, buscando con ello equipar (sic) y armonizar las exigencias del interés público social con la garantía de los derechos del contratista ${ }^{10}$ (mis subrayados).

De todo lo dicho, resulta claro que, en los contratos de la administración pública, las partes contratantes pactan unas determinadas prestaciones que son correspondientes entre sí, las cuales deben mantenerse durante toda la ejecución del contrato y hasta la finalización del mismo. La modificación de estas condiciones, incluso por razones ajenas a los cocontratantes, generan una alteración o una ruptura en el equilibrio económico del contrato, de donde nace el deber de restablecer las condiciones previstas al momento de proponer - en caso de licitación o concurso público — o de contratar — en caso de contratación directa—.

En este sentido, el Consejo de Estado de Colombia ha dicho:

Ha sido una constante en el régimen jurídico de los contratos que celebra la administración pública, reconocer el derecho del contratista al mantenimiento del equilibrio económico del contrato, como quiera que la equivalencia de las prestaciones recíprocas, el respeto por las condiciones que las partes tuvieron en cuenta al momento de su celebración y la intangibilidad de la remuneración del contratista, constituyen principios esenciales de esa relación con el Estado ${ }^{11}$.

9 Corte Constitucional: sentencia C-892 de 2001.

10 lbíd.

11 Consejo de Estado, Sala de lo Contencioso Administrativo, sección tercera: sentencia del 29 de mayo de 2003, expediente 14.577 (R-4028). 
Podemos concluir, entonces, que el principio del equilibrio económico de los contratos administrativos consiste en que las prestaciones que las partes pactan de acuerdo con las condiciones tomadas en consideración al momento de presentar la propuesta o celebrar el contrato, deben permanecer equivalentes hasta la terminación del mismo, de tal manera que, si se rompe esa equivalencia, nace para el afectado el derecho a una compensación pecuniaria que la restablezca.

\section{ANTECEDENTES Y ORIGEN DEL EQUILIBRIO ECONÓMICO EN LOS CONTRATOS ADMINISTRATIVOS}

\section{II.1. El tránsito del principio de riesgo y ventura al del equilibrio económico en el contrato administrativo}

El Derecho romano se caracterizó por no formular soluciones generales a los problemas jurídicos, sino por dar soluciones a los casos concretos, a partir de las cuales los comentaristas modernos han podido extraer reglas para soluciones más generales. El tema de la equivalencia de prestaciones en los contratos conmutativos no fue la excepción. En efecto, los juristas romanos se limitaron a dar ejemplos de cómo distribuir los riesgos en algunas situaciones específicas que acaecen en el desarrollo de ciertos tipos contractuales. La doctrina, a partir de estos ejemplos, ha podido construir soluciones para algunos tipos contractuales: así, en la compraventa, no se exige el equilibrio económico entre las prestaciones en la medida en que la lesión opera excepcionalmente; en el arrendamiento, bajo el principio de la buena fe, se han construido técnicas de distribución de la responsabilidad por la pérdida de la cosa, y en el contrato de obra, bajo la noción de equidad, se deduce que los riesgos de la obra no deben ser soportados íntegramente por una sola de las partes, sino que se deben distribuir uniformemente entre ellas ${ }^{12}$. Se observa, entonces, que ya en el Derecho romano existen antecedentes de la búsqueda del equilibrio económico del contrato, aunque sin una vocación general, sino, más bien, con relación a algunos contratos específicos.

Bajo la influencia del Derecho canónico, en el Derecho de la Edad Media se aplicó la idea de San Agustín del iustum pretium (precio justo), que permitió a los juristas de esa época extender la solución de la lesión a toda clase de contratos, como un dolo objetivo que constituye un vicio del consentimiento. Así, por ejemplo, en el contrato de obra, si el valor de ejecución superaba en más de la mitad el valor pactado, el contratista podía pedir que el contratante pagara el valor completo de la obra. En otras palabras, cuando acaecía un riesgo y se presentaba una 
disconformidad entre el precio pactado y el iustum pretium en el Derecho canónico, se imponía el precio justo y se modificaba el pacto contractual.

Estos antecedentes del Derecho canónico resultan trascendentales para el Derecho administrativo contemporáneo en la medida en que, como la administración pública actual, la Iglesia de la Edad Media gozaba de una posición de prevalencia respecto de los particulares, por lo cual las soluciones y técnicas adoptadas por ese Derecho pueden servir de referencia, en algunos casos, a las del actual Derecho administrativo ${ }^{13}$. El Derecho canónico, en últimas, pretendía restar rigor al principio del pacta sunt servanda, según el cual los contratos son ley para las partes y deben ser cumplidos en los estrictos términos en que fueron pactados, al considerar que en los contratos de tracto sucesivo se debía entender pactada la cláusula rebus sic stantibus, conforme a la cual los contratos se entienden celebrados bajo la condición de que subsistan las circunstancias bajo las cuales se contratón ${ }^{14}$.

El Derecho privado de comienzos del siglo xix, bajo la concepción individualista y liberal del contrato, se nutrió tanto del Derecho romano como del Derecho canónico, pero configuró un sistema en el cual el imperio de la lex contractus y del principio del pacta sunt servanda era poco menos que absoluto, con lo cual resultaba limitada, en términos generales, la posibilidad de que un contrato pudiera, en la etapa de su ejecución, ser sometido a modificaciones por causa de haber variado las circunstancias tenidas en cuenta al momento de su celebración y por haber quedado, como consecuencia de esa alteración, rota la conmutatividad o equivalencia inicial de las prestaciones ${ }^{15}$. Es así como la mayoría de legislaciones civiles basadas en el Code Civil francés de 1804 establecieron que, a falta de norma legal que expresamente lo permitiera, la ruptura de la llamada ecuación o equilibrio financiero del contrato conmutativo, producida sorpresivamente por causas sobrevinientes a la formación del mismo, no podía llevar a restablecer entre las partes el equilibrio de esa manera perturbado y, por lo mismo, no era posible la revisión de las prestaciones estipuladas.

El contrato de la administración, que nace al amparo del contrato de Derecho privado en la medida en que se trataba de un típico acto de gestión de la administración, toma originalmente del Derecho privado esta idea de estricta aplicación del principio pacta sunt servanda y de la obligación de que los contratos deben ejecutarse de buena fe, a lo cual le suma el ingrediente del interés general, que obliga a la administración

13 lbíd., pp. 36 y siguientes.

14 Sobre la cláusula rebus sic stantibus, véase Corsi, Luis. "Alteraciones económicas y obligaciones contractuales: la cláusula rebus sic stantibus en la contratación administrativa". En El Derecho público a comienzos del siglo XX. Estudios en homenaje al profesor Allan R. Brewer Carías. Madrid: Editorial Civitas, 2003, pp. 1779 y siguientes.

15 Véase Escobar Gil, Rodrigo. Teoría general de los contratos de la administración pública. Bogotá: Legis Editores, 2003, pp. 409 y siguientes.

EL EQUILIBRIO

ECONÓMICO EN LOS CONTRATOS ADMINISTRATIVOS

THE ECONOMIC BALANCE IN ADMINISTRATIVE CONTRACTS 
a tener certeza sobre su propio presupuesto, y le permite exigir una diligencia especial a su cocontratante, así como adoptar una mayor severidad para lograr el cumplimiento del cometido del contrato ${ }^{16}$. La consecuencia de esta concepción del contrato de la administración en el siglo xix, especialmente en relación con el contrato de obra pública pactado a precio fijo o alzado, es la aplicación del principio del riesgo y ventura, conforme al cual el cocontratante de la administración tenía la carga de ejecutar el contrato en los términos económicos en que fue pactado, sin importar que la concreción de los riesgos — sin distinción alguna entre ellos - le hiciera mucho más onerosa la ejecución. En palabras de García de Enterría, "como el constructor ha de entregar la obra conclusa a cambio de un precio alzado, asume la mayor (riesgo) o menor (ventura) onerosidad que pueda significar la obtención del resultado; lo único que importa es el resultado"17.

El riesgo y ventura constituye, entonces, el criterio de general aplicación a todos los supuestos de aumento del costo del contrato por cualquier causa, y la posibilidad de reconocer el efecto de las modificaciones en las condiciones contractuales se limitaba a casos excepcionales derivados del aumento de las prestaciones por orden de la administración.

Con el advenimiento de la teoría del servicio público, junto con el reconocimiento de la necesidad de imponer un contrapeso a los poderes exorbitantes de los que gozaba la administración en los contratos administrativos — justificados en la necesidad de lograr la prestación efectiva, regular y continua de los servicios públicos_-, la jurisprudencia francesa comenzó a aceptar la idea de la necesidad de mantener el equilibrio económico de los contratos administrativos. El primer antecedente conocido se encuentra en las conclusiones del comisario Leon Blum previas al fallo del Consejo de Estado francés de 21 de marzo de 1910, Compagnie générale française des tramways, en el cual se acoge el cambio jurisprudencial propuesto por el comisario de gobierno. El citado comisario, después de recordar la necesidad de mantener una prestación eficiente y continua del servicio público y de que el contratista, como colaborador, tiene derecho a una compensación por la utilización de los poderes exorbitantes por parte de la administración, concluyó que "en todo contrato de concesión está implicada, como un cálculo, la honesta equivalencia entre lo que se concede al concesionario y lo que se le exige. Es lo que se llama la equivalencia comercial, la ecuación financiera del contrato de concesión"18.

16 Véase Villar Palasí, José Luis. Lecciones sobre contratación administrativa. Madrid: Sección de publicaciones de la Universidad de Madrid, 1969, pp. 161 y siguientes.

17 García de Enterría, Eduardo y Tomás Ramón Fernández. Curso de Derecho administrativo I. Décimo segunda edición. Madrid: Editorial Civitas, 2004, p. 749.

18 El texto de las conclusiones del comisario de gobierno, así como del fallo del Consejo de Estado, puede consultarse en Marceau Long et al. Les grands arrêts de la jurisprudence administrative. Décimo quinta edición. París: Dalloz, 2005, pp. 131 y siguientes. 
A partir de ese antecedente, la doctrina y la jurisprudencia francesas continuaron construyendo la noción del equilibrio económico del contrato administrativo, hasta el punto de que, en la actualidad, no se habla del principio de riesgo y ventura como principio rector del contrato administrativo, sino de la necesidad de mantener la equivalencia entre las prestaciones pactadas, de tal manera que el cocontratante de la administración tiene derecho a un precio cierto en la ejecución del contrato, a la intangibilidad de su remuneración. Podemos afirmar, entonces, que es en Francia donde nace y se consolida el principio del equilibrio económico como noción dominante de la fase de ejecución de los contratos administrativos ${ }^{19}$.

\section{II.2. La aceptación y consolidación del principio de equi- librio económico en el contrato administrativo en Colombia ${ }^{20}$}

Durante el siglo xix y buena parte del siglo xx, los contratos celebrados por la administración pública colombiana fueron regidos por el Derecho privado, salvo en algunos aspectos puntuales - como la cláusula de caducidad, introducida en el Derecho colombiano a comienzos del siglo $\mathrm{xx}$-, a los cuales se aplicaban regulaciones especiales, expresamente consagradas por el legislador. En este orden de ideas, hasta bien entrado el siglo xx, en Colombia no existían verdaderos contratos administrativos, sino contratos de Derecho privado de la administración con algunas normas de Derecho público aplicables ${ }^{21}$. En lo que tiene que ver con el régimen jurídico del precio que debía pagar la administración a su cocontratante por la ejecución de las prestaciones pactadas, que es el tema objeto del presente escrito, la solución dada por el ordenamiento jurídico colombiano se traducía en la aplicación del Derecho privado que, según lo señalamos atrás, se encontraba guiado por una concepción liberal e individualista del contrato, conforme a la cual el imperio de la lex contractus y el principio del pacta sunt servanda hacían que fuera poco menos que imposible la revisión de los contratos por alteración en las circunstancias tomadas en consideración al momento de celebrar los contratos.

Los primeros intentos normativos por romper con el principio de riesgo y ventura empezaron en la década de 1960. En primer lugar, con

19 Idéntica conclusión es expuesta por Gaspar Ariño Ortíz en la página 241 de su libro Teoría del equivalente económico en los contratos administrativos.

20 Un estudio sobre la evolución de esta figura en el derecho colombiano, puede verse en Escobar Gil, Rodrigo. Teoría general de los contratos de la administración pública. Ob. cit., pp. 417 y siguientes.

21 En relación con algunos aspectos históricos de los contratos administrativos en Colombia, véase Vidal Perdomo, Jaime. "La noción de contrato estatal en Derecho colombiano". En Homenaje a Dalmacio Vález Sarsfield. Tomo V. Córdoba: Academia Nacional de Derecho y Ciencias Sociales de Córdoba, 2000, pp. 457 y siguientes; y Rodríguez Rodríguez, Libardo. Derecho administrativo. General y colombiano. Décimo sexta edición. Bogotá: Editorial Temis, 2008, pp. 415 y siguientes. 
la expedición de la ley 4 de 1964, cuyo artículo 11 previó que en los contratos de obra, tanto a precio global como a precios unitarios, era imperativo pactar el reajuste de precios, y tener en cuenta la variación de cualquiera de los factores determinantes de los costos previstos al momento de contratar. Posteriormente, la ley 36 de 1966, que consagraba normas relacionadas con los contratos adicionales, dispuso que cuando "por reajuste de precios, cambio de especificaciones y otras causas imprevistas" hubiere necesidad de modificar el valor pactado inicialmente, debía celebrarse un contrato adicional que así lo estipulara.

Desde el punto de vista jurisprudencial, la institución del equilibrio económico en los contratos administrativos empieza a tener auge en Colombia a partir de la década de 1970. En efecto, fue necesario esperar hasta 1972 para que la Sala de Consulta y Servicio Civil del Consejo de Estado, en ejercicio de su función meramente consultiva, con fundamento en las normas citadas y siguiendo las teorías francesas sobre la materia, manifestara que tal institución podía ser perfectamente aplicable en los contratos administrativos. En este sentido, manifestó que "el régimen jurídico del contrato administrativo descansa sobre dos ideas fundamentales: si de una parte afirma la existencia en favor de la administración de prerrogativas exorbitantes del derecho común de los contratos, de otra reconoce el derecho del contratante al respecto del equilibrio financiero considerado en el contrato"22.

Hasta donde tenemos noticias, la primera aplicación práctica de esta figura se produjo también en 1972, aunque no fue la jurisprudencia de lo contencioso administrativo quien la hizo, sino la jurisprudencia arbitral. En efecto, en esa ocasión, el Tribunal de Arbitramento descartó la aplicación de las normas de Derecho privado a un contrato administrativo de obra pública, al considerar que, a pesar de que conforme al Derecho común una vez perfeccionado el contrato este era absolutamente inmutable, a la luz de las estipulaciones del contrato de obra pública, el equilibrio económico podía ser restablecido cuando ello fuere justo y cuando la alteración de las condiciones contractuales no obedeciera a causas imputables al propio contratista. Esto, finalmente, condenó a la entidad pública demandada al restablecimiento del equilibrio económico del contrato ${ }^{23}$.

A partir de entonces se consolida, tanto jurisprudencial como normativamente, la aplicación de la teoría del equilibrio económico en los contratos administrativos ${ }^{24}$. En efecto, el decreto ley 150 de 1976,

22 "Consejo de Estado, Sala de Consulta y Servicio Civil" (concepto de 11 de marzo de 1972). En Anales del Consejo de Estado. Tomo LXXXII, números 433-434, primer trimestre de 1972, p. 25.

23 "Tribunal de Arbitramento de Imprese Italiane All "Estero SPA", Impresit del Pacífico S.A., Octavio Bertolero Cía., y Contratistas Generales S.C. de R.L contra Empresa de Energía Eléctrica de Bogotá". En Laudos arbitrales - versión cd (laudo del 11 de diciembre de 1972). Bogotá: Cámara de Comercio de Bogotá, septiembre de 2005.

24 Como expresiones de la jurisprudencia sobre el principio del equilibrio económico, véanse "Tribunal de Arbitramento de Termocolombia contra Instituto Colombiano de Energía Eléctrica -ICEL" (laudo 
que aunque de efímera vigencia ha sido considerado como el primer estatuto de contratación de la administración pública en Colombia, en su artículo 74, previó para los contratos de obra —a precio alzado o a precios unitarios- la revisión periódica de precios "en función de las variaciones que ocurran en los factores determinantes de los costos" Posteriormente, la ley 19 de 1982, en sus artículos 6 y 8, consagró de forma mucho más expresa la figura, al disponer que, de una parte, en caso de modificación de los contratos administrativos ordenada por la misma administración por razones de interés general —que le generara mayores costos al contratista-, este tendría derecho a que la administración se los reembolsara y, de otra, que en caso de terminación unilateral por inconveniencia o inoportunidad de los contratos, el contratista tendría derecho al pago de los perjuicios causados por esta decisión.

A su vez, el decreto ley 222 de 1983, expedido con base en las facultades extraordinarias conferidas por la ley 19 de 1982, avanzó aun más en la consolidación de la aceptación del principio del equilibrio económico del contrato administrativo. En este sentido, son varias las disposiciones que expresan su aplicación:

a. cuando se terminaba unilateralmente el contrato por razones de orden público o coyuntura económica crítica, el contratista tenía derecho a la indemnización de los daños que tal decisión le comportara (artículo 19);

b. cuando por interés público se hiciere indispensable la modificación de los contratos administrativos, entre otros requisitos, las entidades estatales debían respetar las ventajas económicas que hubieren otorgado al contratista, guardar el equilibrio financiero del contrato y reconocer al contratista los nuevos costos provenientes de la modificación (artículo 20);

c. cuando hubiere necesidad de modificar el valor contractualmente pactado, debía celebrarse un contrato adicional que así lo estipulara (artículo 58); y

de 16 de marzo de 1979); Consejo de Estado, Sala de lo Contencioso Administrativo, Sección Tercera: sentencia del 18 junio 1979, expediente 1.694-1.677. En Anales del Consejo de Estado. Tomo XCVI, números 461-462, segundo semestre de 1979, pp. 561 y siguientes; y, especialmente, Consejo de Estado, Sala de lo Contencioso Administrativo, Sección Tercera: sentencia del 20 de septiembre de 1979, expediente 2.742, en el cual se hace una presentación general de las normas y la jurisprudencia administrativa y arbitral relacionadas con el equilibrio económico del contrato identificadas por el Consejo de Estado hasta ese momento, donde se cita, para el efecto, el concepto del 11 marzo 1972 de la Sala de Consulta y Servicio Civil del Consejo de Estado, el laudo arbitral que dirimió las controversias entre el arquitecto Rojas Álvarez y el Instituto Colombiano de los Seguros Sociales (respecto del cual no indica la fecha), el laudo arbitral del 16 de junio de 1976 que dirimió las controversias entre Mitsubishi Heavy Industries y el Instituto Colombiano de Energía Eléctrica (icel), y el laudo arbitral del 3 diciembre de 1977, el cual dirimió las controversias entre Konstruktor Split Yugoeslavia y Empresa de Acueducto y Alcantarillado de Bogotá.

25 Una exposición del estatuto de contratación de 1976 puede consultarse en Lamprea, Pedro A. Contratos administrativos: tratado teórico y práctico. Bogotá: Fondo de Cultura Jurídica, 1979. 
d. en los contratos de obra, a precio global o a precios unitarios, debía pactarse la revisión periódica de precios teniendo en cuenta las variaciones que ocurrieran en los factores determinantes de los costos (artículo 86).

En cuanto al tema del equilibrio económico de los contratos, la importancia del estatuto de contratación de 1983 radica en que, por una parte, amplió los supuestos con fundamento en los cuales podían adoptarse las decisiones específicas que dispusieran el restablecimiento de ese equilibrio y, por otra, dejó claro que el equilibrio es una figura que se aplica a toda clase de contratos administrativos de tracto sucesivo y no solamente a los contratos de concesión y de obra pública, como parecía deducirse de la normatividad anterior ${ }^{26}$. Además, con fundamento en las normas del decreto ley 222 de 1983, la jurisprudencia contenciosoadministrativa aceptó sin vacilaciones que uno de los derechos del cocontratante de la administración —en su calidad de colaborador- se traduce en el mantenimiento de las condiciones económicas pactadas; es decir, en el mantenimiento del equilibrio económico del contrato ${ }^{27}$.

Con posterioridad, siguiendo un mandato constitucional y con la finalidad de corregir los errores que supuso la aplicación en la práctica de la normatividad consagrada en el decreto ley 222 de 1983, el Congreso de Colombia expidió la ley 80 de 1993 como nuevo estatuto de contratación de la administración pública ${ }^{28}$. Entre los aportes que es preciso resaltar, esta ley pretendió eliminar la distinción entre contratos administrativos y contratos de Derecho privado de la administración, al crear una supuesta categoría unitaria de contratos bajo la denominación de "contratos estatales". No obstante, como lo hemos hecho notar en nuestro manual de Derecho administrativo, los llamados "contratos estatales" son verdaderos contratos administrativos, en la medida en que, si bien tienen un régimen jurídico mixto, lo cierto es que ese régimen está conformado por reglas especiales que los diferencia de los contratos entre particulares ${ }^{29}$.

26 Una exposición del sistema contractual administrativo de 1983, incluido el principio del equilibrio económico del contrato, puede consultarse en Rodríguez, Gustavo Humberto. Contratos administrativos. Tercera edición. Bogotá: Librería Jurídica Wilches, 1988; y en González Rodríguez, Miguel. La contratación administrativa en Colombia. Bogotá: Librería Jurídica Wilches, 1990.

27 Véase Consejo de Estado, Sala de lo Contencioso Administrativo, sección tercera: sentencia de 4 de septiembre de 1986, expediente 1.677 .

28 Véase la exposición de motivos del proyecto de ley 149 de 1992, que diera lugar a la expedición de la ley 80 de 1993 en Betancur Cuartas, Jaime. Nuevo estatuto general de la contratación administrativa. Medellín: Biblioteca Jurídica Diké, 1993, pp. 97 y siguientes.

29 Véase Rodríguez Rodríguez, Libardo. Derecho administrativo. General y colombiano. Ob. cit., pp. 420 y siguientes. La doctrina colombiana ha coincidido en afirmar que la consagración legal de los llamados "contratos estatales", aunque tienen un régimen jurídico mixto, no implica la supresión de la figura del contrato administrativo, la cual no ha desaparecido del derecho colombiano. Con este fin, véase Vidal Perdomo, Jaime. "La noción de contrato estatal en derecho colombiano". Ob. cit., p. 465 y siguientes; Benavides, José Luis. El contrato estatal. Ob. cit., p. 489; y Expósito Vélez, Juan Carlos. La configuración del contrato de la administración pública en derecho colombiano y español. Bogotá: Universidad Externado de Colombia, 2003, pp. 253 y siguientes, y 329 y siguientes. 
En consecuencia, para los efectos de este trabajo, cuando nos referimos a los contratos administrativos — que es la terminología aceptada en el Derecho comparado para referirse a los contratos de la administración pública sometidos a un régimen jurídico especial—, deben considerarse cobijados también los en Colombia llamados "contratos estatales".

Otra de las novedades del actual estatuto de contratación estatal, contenido en la ley 80 de 1993, es la de haber reconocido ampliamente el derecho de los cocontratantes - no solo del contratista - a que se mantenga la equivalencia en las prestaciones pactadas. En efecto, la citada ley consagra de manera amplia en su artículo 27 , como un verdadero principio de la contratación administrativa, el de la "ecuación contractual" en los siguientes términos: "en los contratos estatales se mantendrá la igualdad o equivalencia entre derechos y obligaciones surgidos al momento de proponer o contratar, según el caso. Si dicha igualdad o equivalencia se rompe por causas no imputables a quien resulte afectado, las partes adoptarán en el menor tiempo posible las medidas necesarias para su restablecimiento".

En concordancia con ese principio de la ecuación contractual, los numerales 8 y 9 del artículo 4 de la misma ley 80 de 1993 establecen entre los deberes de las entidades estatales contratantes que estas "adoptarán las medidas necesarias para mantener durante el desarrollo y ejecución del contrato las condiciones técnicas, económicas y financieras existentes al momento de proponer", y "actuarán de tal modo que por causas a ellas imputables, no sobrevenga una mayor onerosidad en el cumplimiento de las obligaciones a cargo del contratista".

A su vez, el numeral 1 del artículo 5 del mismo texto señala que los contratistas:

[...] tendrán derecho a recibir oportunamente la contraprestación pactada y a que el valor intrínseco de la misma no se altere o se modifique durante la vigencia del contrato. En consecuencia tendrán derecho, previa solicitud, a que la administración les restablezca el equilibrio de la ecuación económica del contrato a un punto de no pérdida por la ocurrencia de situaciones imprevistas que no sean imputables a los contratistas. Si dicho equilibrio se rompe por incumplimiento de la entidad estatal contratante, tendrá que restablecerse la ecuación surgida al momento del nacimiento del contrato.

Finalmente, desde el punto de vista del Derecho positivo, vale decir que de conformidad con el artículo 28 de la citada ley: "en la interpretación de las normas sobre contratos estatales... se tendrán en consideración los fines y principios de que trata esta ley, los mandatos de la buena fe y la igualdad y el equilibrio entre prestaciones y derechos que caracteriza los contratos conmutativos" (mis subrayados). 
Resulta, pues, evidente que, en la actualidad, la normatividad positiva reconoce - con una precisión incuestionable- el derecho de las partes de un contrato administrativo al mantenimiento de su equilibrio económico, esto es, al mantenimiento de la equivalencia entre las prestaciones pactadas. Igualmente, como lo veremos más adelante, la jurisprudencia, además de aplicar consistentemente la figura del equilibrio económico, la ha ido modelando y transformando para darle la fisonomía de la cual goza hoy en día, al punto de reconocer que se trata de un imperativo legal que no puede ser dejado simplemente a la voluntad contractual de las partes; es decir, que se aplica en todos los eventos en que se suscriben contratos administrativos conmutativos de tracto sucesivo o de ejecución diferida, que son, precisamente, los negocios jurídicos respecto de los cuales tiene vigencia el principio del equilibrio económico y financiero.

Esta postura ha sido ampliamente desarrollada por el Consejo de Estado en su jurisprudencia reciente, en la cual se ha sostenido al respecto que:

[...] la ecuación financiera del contrato es una figura de imperativo legal, que se aplica con independencia de que las partes la hubieran pactado o no. En otros términos la sala reitera que es el propio legislador quien fija las reglas tendientes a procurar el equilibrio financiero del contrato conmutativo cuando este se rompa por aquellos casos no imputables al contratista, por distintas circunstancias [...].

Y más adelante afirma:

Tiene entonces, suficiente sustento, en legislación y jurisprudencia, el concepto de equilibrio financiero del contrato y, por consiguiente, no podía resultar extraño para el tribunal de arbitramento la aplicación de dicha figura, bajo la óptica fundamental que el Estado pudiera cumplir con los fines previstos y que el consorcio contratista, a su vez, por no tener obligación legal ni contractual de trabajar a pérdida, lograra obtener el lucro inherente y previsto para su actividad. Si el fallador encontraba rota o alterada la ecuación financiera del contrato por causas imputables y de especial consideración, ajenas al contratista, le corresponde acudir a dicha figura, no solo por el mandato legal, sino por motivaciones de justicia y equidad inherentes al equilibrio financiero contractual ${ }^{30}$.

En concordancia con lo anterior, la jurisprudencia constitucional también ha manifestado que "la relación sinalagmática del contrato se asume como un mero desarrollo del principio de justicia conmutativa que, con carácter de derecho imperativo, — se ha dicho ya — justifica la traslación de los riesgos extraordinarios que operan durante la vigencia 
del negocio jurídico a la Administración Pública, con independencia de que estos se hubieren pactado o no en el texto formal del acuerdo de voluntades" ${ }^{\prime 1}$.

De los anteriores pronunciamientos se desprende, claramente, que el mantenimiento del equilibrio financiero del contrato es hoy una obligación que se impone a las partes desde el mismo ámbito legislativo, razón por la cual no puede supeditarse, por razones de justicia y equidad, la búsqueda de herramientas que pretendan este objetivo a la existencia de un previo acuerdo entre las partes y mucho menos a la liberalidad de la entidad contratante.

\section{JUSTIFICACIÓN DE LA EXISTENCIA DEL PRINCIPIO DEL EQUILIBRIO ECONÓMICO EN LOS CONTRATOS ADMINISTRATIVOS}

Teniendo en cuenta que el principio del equilibrio económico de los contratos administrativos nació como un derecho exclusivo del cocontratante de la administración, las primeras justificaciones de su existencia - las cuales aún mantienen vigencia - se orientaron a demostrar la razón de ser de ese derecho del cocontratante particular.

En primer lugar, desde la misma formulación del principio por parte del comisario de gobierno Leon Blum, la teoría del servicio público ha jugado un papel trascendental. En efecto, frente a la necesidad de una prestación continua y eficiente del servicio público, que obligaba al cocontratante de la administración a no suspender la ejecución del contrato en aquellos eventos en que - por circunstancias de hecho sobrevinientes e imprevistas - se alteraran las condiciones tenidas en cuenta al momento de configurar el negocio, el contratista debía tener el derecho a ser resarcido por los mayores valores en que incurrió para la efectiva colaboración en la prestación del servicio público ${ }^{32}$.

A lo anterior se sumó el hecho de que la administración, en los contratos administrativos, goza de ciertas prerrogativas y de una posición de prevalencia sobre su cocontratante, locual debe tener comocontrapartida el derecho del contratista a una indemnización por el ejercicio —aún legal— de tales prerrogativas, de tal manera que no se altere la equivalencia material en las prestaciones pactadas ${ }^{33}$. El fundamento

31 Corte Constitucional: sentencia C-892 de 2001.

32 Véase Jèze, Gastón. Principios generales del derecho administrativo. Tomo V. Buenos Aires: Ediciones Depalma, 1950, pp. 16 y siguientes. En este sentido, también puede verse Ariño Ortíz, Gaspar. Teoría del equivalente económico en los contratos administrativos. Ob. cit., p. 243; y Cassagne, Juan Carlos. "El equilibrio económico-financiero del contrato administrativo". En Estudios de derecho público. Buenos Aires: Ediciones Depalma, 1995, p. 136.

33 Véase De Laubadère, André e Yves Gaudemet. Traité de droit administratif. Ob. cit., Tomo I, número 1466; y Richer, Laurent. Droit des contrats administratifs, Cuarta edición. París: LGDJ, 2004, número 333.

EL EQUILIBRIO ECONÓMICO EN LOS CONTRATOS ADMINISTRATIVOS

THE ECONOMIC BALANCE IN ADMINISTRATIVE CONTRACTS 
jurídico del derecho al mantenimiento del equilibrio económico — desde esta perspectiva, y sin perjuicio del Derecho positivo- se encuentra en los fines de interés público que tienen los contratos administrativos y en el carácter de colaborador del cocontratante de la administración, que obligan a concluir que el patrimonio del cocontratante no puede ser sacrificado y que, a la vez, debe darse una equivalencia honesta entre las prestaciones ${ }^{34}$.

El derecho del cocontratante al mantenimiento del equilibrio económico del contrato también ha encontrado una justificación en principios constitucionales. En efecto, se ha sostenido que el deber general que tiene el Estado de reparar los daños antijurídicos generados por sus actuaciones, la obligación de mantener la igualdad ante las cargas públicas, la garantía del patrimonio de los particulares, y el deber de garantizar la vida, honra y bienes de las personas, sostienen que el cocontratante de la administración tiene el derecho a que su remuneración en un contrato administrativo se mantenga intangible, a pesar de que ocurran acontecimientos que alteren las condiciones tenidas en cuenta al momento de proponer o contratar, según sea el caso ${ }^{35}$.

No obstante la trascendencia y vigencia actual de las justificaciones expuestas, si se tiene en cuenta que a pesar de que tradicionalmente el derecho al mantenimiento del equilibrio económico del contrato se ha reconocido solo al cocontratante de la administración, en estricto sentido también puede reconocerse a la administración misma. Por ello es preciso buscar una justificación más amplia, que comprenda la totalidad de situaciones que permiten aplicar el principio del equilibrio económico del contrato. En ese sentido, puede considerarse que los argumentos que fundamentan el derecho al mantenimiento del equilibrio económico del contrato administrativo son, por un lado, la conmutatividad propia de los contratos administrativos — que, por definición, son sinalagmáticos—- así como, por otro lado, el deber de aplicar una cierta justicia contractual.

La relación intrínseca entre el principio del mantenimiento de la ecuación financiera en los contratos estatales y su carácter conmutativo fue expresado por la jurisprudencia francesa desde principio del siglo XX al afirmar que "es de la esencia de toda concesión el buscar y realizar, en la medida de lo posible, una igualdad entre las ventajas que le son

34 Véase Escola, Héctor Jorge. Tratado integral de los contratos administrativos. Ob. cit., volumen I, número 104. En igual sentido, puede consultarse a la Corte Constitucional en su sentencia C-892 de 2001.

35 Esta fundamentación es expuesta en Escobar Gil, Rodrigo. Teoría general de los contratos de la administración pública. Ob. cit., pp. 427 y siguientes. La doctrina argentina comparte parcialmente esta justificación, específicamente en cuanto a la aplicación del principio de igualdad en las cargas públicas. Para esto, véase Cassagne, Juan Carlos. "El equilibrio económico-financiero del contrato administrativo". Ob. cit., p. 137; y Marienhoff, Miguel S. Tratado de Derecho administrativo. Ob. cit., tomo III-A, número 761. 
procuradas al concesionario y las cargas que le son impuestas. Las ventajas y las cargas deben balancearse de manera de contrapesar los beneficios probables y las pérdidas previstas" ${ }^{36}$.

Así, la necesaria equivalencia entre las prestaciones y el deber que tienen las partes dentro de un contrato conmutativo de mantenerla permite, igualmente, fundamentar la consagración legal de la figura del equilibrio económico del contrato. Al tener en cuenta este carácter conmutativo de los contratos administrativos, la doctrina reconoce que existen intereses divergentes de las partes que merecen la tutela del ordenamiento jurídico, procedimiento que se lleva a cabo a través de la aplicación del principio del equilibrio económico y financiero del contrato ${ }^{37}$.

Al carácter conmutativo del contrato administrativo para justificar el reconocimiento del derecho de las partes — no simplemente del contratista- y al mantenimiento del equilibrio económico del contrato, la doctrina ha añadido el elemento de la justicia contractual, el cual, en todo caso, es un concepto estrechamente ligado al de la conmutatividad. Este concepto se refiere, en primer lugar, al de justicia en las prestaciones, lo cual implica que el juicio de justicia no puede hacerse de manera aislada, sino de manera comparativa entre las prestaciones pactadas, por lo que se realiza una comparación entre las obligaciones a cargo de cada una de las partes, con la finalidad de encontrar un necesario equilibrio o una equivalencia material entre las prestaciones contractuales.

El principio de justicia contractual implica también la búsqueda de un equilibrio entre la posición de las partes, pues no cabe duda de que, en ocasiones, la administración se encuentra en una posición de prevalencia respecto de su cocontratante, pero también es cierto que existen otros eventos donde es el cocontratante quien ejerce una posición de superioridad frente a la administración, por gozar de una posición dominante en el mercado. En estos casos, para mitigar las consecuencias de la superioridad de alguna de las partes, el ordenamiento jurídico ofrece como solución la del equilibrio económico del contrato administrativo, con fundamento en el cual las prestaciones de cada una de ellas corresponderán a las prestaciones de la otra, con lo que se logra una equivalencia material entre las mismas ${ }^{38}$. En este sentido, tanto la doctrina internacional como la jurisprudencia colombiana, al hacer referencia al fundamento mismo del deber de restablecimiento del equilibrio económico del contrato, se han referido

36 Consejo de Estado francés, fallo del 21 de marzo de 1910: Compagnie Générale Française des Tranways.

37 Véase Benavides, José Luis. Ob. cit., pp. 565 y siguientes.

38 Sobre la justicia contractual como fundamento del equilibrio económico del contrato administrativo, puede verse Cárdenas Mejía, Juan Pablo. "La justicia contractual". En Ensayos jurídicos. Liber amicorum en homenaje al profesor Carlos Holguín Holguín. Bogotá: Ediciones Rosaristas, 1996, pp. 301 y siguientes. Igualmente, puede verse Emili, Eduardo O. "El equilibrio contractual". En Ismael Farrando (coordinador). Contratos administrativos. Buenos Aires: Abeledo-Perrot, 2002, p. 621.

EL EQUILIBRIO ECONÓMICO EN LOS CONTRATOS ADMINISTRATIVOS

THE ECONOMIC BALANCE IN ADMINISTRATIVE CONTRACTS 
a la necesidad de que la actividad contractual administrativa se guíe por un principio de justicia conmutativa ${ }^{39}$.

En consecuencia, la justicia contractual y la conmutatividad del contrato administrativo también permiten fundamentar el principio del equilibrio económico en el contrato administrativo como derecho de los dos cocontratantes, y no simplemente como derecho del cocontratante particular.

\section{CONDICIONES GENERALES PARA LA PROCEDENCIA DE LA APLICACIÓN DEL PRINCIPIO DEL EQUILIBRIO ECONÓMICO EN LOS CONTRATOS ADMINISTRATIVOS}

No obstante lo expresado hasta ahora, no toda alteración en las condiciones previstas al momento de proponer o de contratar configura jurídicamente la ruptura del equilibrio económico del contrato. Al respecto, se requiere que la alteración cumpla con las condiciones que se desarrollarán a continuación.

\section{IV.1. La alteración debe darse por acontecimientos que no puedan ser imputables a la parte que reclama el restablecimiento}

Para que una alteración en las condiciones contractuales comporte una ruptura en el equilibrio económico del contrato, es condición indispensable que la parte que reclama su restablecimiento no debe haber causado con su propia conducta tal alteración. Esta es una consecuencia lógica de lo expresado atrás, en el sentido de que el deber de restablecer el equilibrio contractual nace como consecuencia de hechos ajenos a las partes o de hechos que provienen de la conducta del cocontratante que no se ha perjudicado ${ }^{40}$.

En otras palabras, para que una circunstancia que altera las condiciones contractuales genere la obligación de restablecimiento de la ecuación contractual, dicha circunstancia no puede ser imputable a la parte perjudicada, ya sea porque se trata de un hecho ajeno al contrato y a la voluntad de los cocontratantes - como es el caso de un cambio en las variables macroeconómicas-, o porque se trate de un hecho de su cocontratante

39 Véase Dromi, Roberto. Derecho administrativo. Quinta edición. Buenos Aires: Ediciones Ciudad Argentina, 1996, p. 558. En igual sentido, puede consultarse a la Corte Constitucional en su sentencia C-892 de 2001, y a la Sección Tercera de la Sala de lo Contencioso Administrativo del Consejo de Estado en sus sentencias del 24 de octubre de 1994, expediente 11.632, y del 2 de febrero de 1996, expediente 8.385 .

40 En relación con esta condición, véase González-Varas Ibáñez, Santiago. El contrato administrativo. Madrid: Editorial Civitas, 2003, p. 274; y Bustelo, Ernesto. "Derechos y obligaciones del contratante particular". En Ismael Farrando (coordinador). Contratos administrativos. Buenos Aires: AbeledoPerrot, 2002, p. 602. 
— como es el caso del incumplimiento de obligaciones contractuales o de una modificación unilateral dispuesta por la administración — ${ }^{41}$.

Este presupuesto necesario para que la alteración en las condiciones contractuales genere el derecho al restablecimiento del equilibrio económico del contrato es una expresión concreta de la máxima del Derecho, conforme a la cual nadie puede alegar su propia culpa en su favor: nemo audiatur propiam turpitudinem allegans. Reconocer lo contrario implicaría premiar la conducta negligente del cocontratante que, en virtud de sus propias actuaciones, alteró las condiciones con fundamento en las cuales se estipularon las obligaciones contractuales.

En relación con esta exigencia, el Consejo de Estado de Colombia ha sido enfático en afirmar que:

[...] el mantenimiento de esas condiciones de ejecución fijadas desde el perfeccionamiento del negocio jurídico, en un momento dado puede resultar especialmente lesivo para una de las partes por la ocurrencia de sucesos imprevistos, posteriores, ajenos a su voluntad y no imputables a incumplimiento del otro contratante, pero que le reportan una mayor onerosidad en el cumplimiento de sus obligaciones, y en consecuencia, se pierde esa equivalencia que se había formado a partir de la celebración del contrato ${ }^{42}$ (mis subrayados).

En una ocasión anterior, el mismo Consejo de Estado había manifestado lo siguiente:

Recuerda esta sala que tienen la doctrina y la jurisprudencia una gran fortaleza en el desarrollo de las teorías que propenden al mantenimiento del equilibrio económico de los contratos que celebran las entidades públicas con los particulares contratistas como colaboradores del Estado, y es ya mandato legal que los contratantes deben mantener la igualdad y equivalencia entre derechos y obligaciones surgidos al momento de contratar, cuando estas se rompen por causas no imputables a quien resultare afectado (mis subrayados) ${ }^{43}$.

\section{IV.2. La alteración debe darse por acontecimientos pos- teriores a la presentación de la propuesta o la cele- bración del contrato}

La segunda condición para que una alteración en las condiciones contractuales determine una ruptura en el equilibrio económico del

41 Sobre este punto, véase Chapus, René. Droit administratif générale. Décimo quinta edición. Tomo I, números 1382 y 1383. París: Montchrestien, 2001. Se distinguen los eventos en que la ruptura proviene de un hecho externo a las partes y de un hecho externo al cocontratante de la administración. 42 Consejo de Estado, Sala de lo Contencioso Administrativo, sección tercera: sentencia del 18 de septiembre de 2003, expediente 1996-05631 (15.119).

43 Consejo de Estado, Sala de lo Contencioso Administrativo, sección tercera: sentencia del 20 de febrero de 1998, expediente 11.101. En el mismo sentido, puede consultarse Consejo de Estado, Sala de lo Contencioso Administrativo, sección tercera: sentencia del 2 de febrero de 1996, expediente 8.385.

\section{EL EQUILIBRIO ECONÓMICO EN LOS CONTRATOS ADMINISTRATIVOS \\ THE ECONOMIC BALANCE IN ADMINISTRATIVE CONTRACTS}


contrato estatal consiste en que el hecho determinante de la ruptura de ese equilibrio debe haber acaecido con posterioridad a la presentación de la propuesta o a la celebración del contrato, según el caso. En otras palabras, el hecho determinante de la alteración de las condiciones contractuales no puede ser anterior a la presentación de la propuesta o a la celebración del contrato, pues, en tal caso, esa circunstancia debió haber sido prevista por las partes al momento de presentar la propuesta o de celebrar el contrato ${ }^{44}$.

En relación con esta exigencia, la jurisprudencia del Consejo de Estado colombiano se ha pronunciado en el sentido de que:

[...] solo puede afirmarse que hay desequilibrio financiero en presencia de contratos conmutativos y de tracto sucesivo, cuando se alteren las condiciones económicas pactadas al momento de su celebración en perjuicio de una de las partes, cuando la alteración sea fruto de hechos ocurridos con posterioridad a la celebración del contrato y cuando estos hechos no sean imputables a quien alega el desequilibrio (mis subrayados) ${ }^{45}$.

\section{IV.3. La alteración debe superar el álea normal}

Para que una alteración en las condiciones contractuales genere una ruptura en el equilibrio económico del contrato se requiere que la alteración supere el álea normal propia de los contratos sinalagmáticos, ya que solo el álea anormal o extraordinaria da lugar al derecho al restablecimiento del equilibrio. En efecto, mientras los áleas normales son una carga que debe asumir el contratista, no sucede así con los anormales; esto es, aquellos que no entraron dentro de las previsiones de las partes al momento de contratar o de proponer, y que deben ser asumidos por la administración. En otras palabras, el cocontratante particular debe soportar el riesgo normal de la ejecución, pero no el anormal que lo privaría de las ganancias razonables que habría obtenido de mantenerse las condiciones iniciales ${ }^{46}$.

Sobre este aspecto, la doctrina ha dicho que:

[...] el derecho al restablecimiento de la ecuación contractual se funda en circunstancias anormales y excepcionales. Álea extraordinaria o anormal es el acontecimiento que frustra o excede de todos los

44 La doctrina francesa ha resaltado el carácter posterior del hecho perturbador. Sobre este tema, véase De Laubadère, André e Yves Gaudemet. Traité de droit administratif. Óp. cit., tomo I, número 1482. La doctrina latinoamericana también ha coincidido en resaltar el carácter posterior del hecho que altera las condiciones contractuales: véase Sayagués Laso, Enrique. Tratado de Derecho administrativo. Octava edición. Tomo I. Montevideo: Fundación de Cultura Universitario, 2002, p. 564.

45 Consejo de Estado, Sala de lo Contencioso Administrativo, sección tercera: sentencia del 4 de septiembre de 2003, expediente 1989-05337 (10883).

46 Sobre el deber de soportar el riesgo normal - pero no el anormal o extraordinario- que supone la ejecución de un contrato administrativo, véase Escola, Héctor Jorge. Tratado integral de los contratos administrativos. Ob. cit., tomo I, número 104; y Parada, Ramón. Derecho administrativo I. Parte general. Décimo segunda edición. Madrid: Editorial Marcial Pons, 2000, p. 346. 
cálculos que las partes pudieron hacer al momento de formalizar el contrato. No está instituido, entonces, para amparar las contingencias normales que ordinariamente se presentan durante la ejecución del contrato. De hecho la realización de cualquier negocio implica unos riesgos normales [...] Por lo tanto, la ecuación no se erige en una protección a ultranza de todos los riesgos del negocio ni por tanto una garantía absoluta de utilidades. Lo será para eventos anormales que escapan a lo habitual del negocio según la especialidad del contratista, las circunstancias internas y externas que rodean la ejecución, la imprevisión de los efectos, etc ${ }^{47}$.

En similar sentido, la jurisprudencia ha entendido que "en todo contrato con el Estado, el contratista debe soportar a su propio costo el álea normal de toda negociación pero no el álea anormal, y por lo tanto en este último evento las consecuencias deben serle resarcidas o atenuadas"48.

Por supuesto, el carácter anormal o extraordinario del álea debe ser acreditado debidamente por el cocontratante perjudicado. En efecto, quien alega un daño y pretende que el mismo sea resarcido tiene la carga de probar la existencia de los elementos que jurídicamente se requieren para su resarcimiento ${ }^{49}$.

Este presupuesto para que se configure el derecho al restablecimiento del equilibrio financiero y económico del contrato consiste, entonces, en que las circunstancias que desequilibran la economía del contrato no sean de aquellas que se inscriben dentro de los riesgos normales de todo negocio jurídico. El contratista —en el desarrollo de su actividad- se debe enfrentar a determinadas contingencias previsibles desde el ejercicio de su actividad como profesional, por lo cual se dice que no puede pretenderse que se cubran absolutamente todos los riesgos a los que tienen que enfrentarse las partes en el desarrollo contractual ${ }^{50}$.

Empero, cuando dichas circunstancias — con independencia de que sean internas o externas a la ejecución - no se enmarcan dentro del cauce de normalidad sino que, al contrario, son excepcionales, anormales y extraordinarias, no nos encontramos ante eventos que deba enfrentar la especialidad de quien contrata con la administración. Estas eventualidades adversas escapan de todas las previsiones razonables que se tuvieron en cuenta al momento de formular la propuesta y de celebrar el contrato. Por ello, de acuerdo con los valores superiores de equidad,

47 Dávila Vinueza, Luis Guillermo. Régimen jurídico de la contratación estatal. Segunda edición. Bogotá: Legis Editores, 2003, pp. 492 y 493.

48 Consejo de Estado, Sala de lo Contencioso Administrativo, sección tercera: sentencia del 2 de septiembre de 2004, expediente 1996-04029 (14.578).

49 En relación con la carga probatoria en materia de responsabilidad del Estado, véase Henao, Juan Carlos. El daño. Bogotá: Universidad Externado de Colombia, 1998, pp. 39 y siguientes.

50 En este sentido puede, verse García de Enterría, Eduardo y Tomás-Ramón Fernández. Curso de Derecho administrativo I. Ob. cit., p. 756.

\section{EL EQUILIBRIO \\ ECONÓMICO EN LOS CONTRATOS \\ ADMINISTRATIVOS \\ THE ECONOMIC \\ BALANCE IN \\ ADMINISTRATIVE \\ CONTRACTS}


justicia e igualdad, el contratista no tiene la obligación de soportar aquellas cargas económicas que se desprenden de este tipo de situaciones, y el ordenamiento jurídico abre la posibilidad de utilizar instrumentos para lograr el restablecimiento ${ }^{51}$.

Como muy bien apunta Marienhoff, el álea extraordinaria o anormal "es el acontecimiento que frustra o excede todos los cálculos que las partes pudieron hacer en el momento de formalizar el contrato" 52 .

Como corolario de lo anterior y en estrecha vinculación con la condición citada en el literal anterior, la calidad de colaborador del contratista no puede supeditarse a un riesgo constante de ganancia o pérdida. Aunque el valor fijado como contraprestación -al cual tiene derecho el contratista - estuviera establecido y delimitado dentro del acuerdo de voluntades, este no puede mantenerse invariable frente a supuestos que obedecen a circunstancias extraordinarias que le son ajenas, y menos aun a circunstancias que son imputables a su cocontratante, pues el precio se fija de acuerdo con las condiciones inicialmente consideradas ${ }^{53}$.

\section{IV.4. La alteración en las condiciones contractuales debe afectar de forma grave y anormal la economía del contrato y el cocontratante perjudicado debe pro- bar tal situación}

Además de que las circunstancias que producen la alteración de las condiciones económicas del contrato deben ser anormales o excepcionales (álea anormal o excepcional), el cocontratante que pide el restablecimiento debe probar la manera en que la alteración en las condiciones de la propuesta o el contrato generó una afectación sobre la economía del contrato. En otras palabras, además de la anormalidad del álea, consideramos que se requiere que el cocontratante perjudicado demuestre que esta afectó de manera también anormal y grave la economía del contrato, lo que hace su ejecución mucho más gravosa. Es decir, no basta un álea anormal o extraordinaria para afirmar que existe una ruptura en el equilibrio económico del contrato, sino que esa álea debe haber generado una alteración notable en la situación económica del contrato, cosa que, como se dijo, hace su ejecución más gravos ${ }^{54}$.

51 Por ello Escola sostiene al abordar esta temática: "En consecuencia, si el cocontratante debe soportar, como en todo contrato, el riesgo normal propio de cualquier negocio, no debe cargar con un riesgo anormal, que lo privaría de las ganancias razonables que hubiera obtenido si la relación contractual hubiera podido cumplirse en las condiciones tenidas en cuenta inicialmente" (Tratado integral de los contratos administrativos. Ob. cit., volumen I, número 104).

52 Marienhoff, Miguel S. Tratado de Derecho administrativo. Ob. cit., tomo III-A, números 761 y 789.

53 Véase Consejo de Estado, Sala de lo Contencioso Administrativo, sección tercera: sentencia del 29 de abril de 1999, expediente 14.855 .

54 En relación con esta condición, véase González-Varas Ibáñez, Santiago. El contrato administrativo. Ob. cit., p. 275; y Escola, Héctor Jorge. Tratado integral de los contratos administrativos. Óp. cit., volumen I, número 104. 
La anterior afirmación es confirmada por la jurisprudencia administrativa colombiana, que si bien algunas veces se limita a expresar que "solo puede afirmarse que hay desequilibrio financiero [...] cuando se alteren las condiciones económicas pactadas al momento de su celebración en perjuicio de una de las partes" pues, el contratista [...] acreditar los riesgos que se hicieron efectivos y los sobrecostos asumidos y cuantificarlos frente al valor del contrato, incluidas las sumas que haya presupuestado en el factor imprevistos; es decir, demostrar la realidad económica del contrato que permita reclamar a la entidad pública contratante el restablecimiento del equilibrio financiero del mismo" ${ }^{26}$.

Y, en otras circunstancias, es expresamente más estricta al afirmar que:

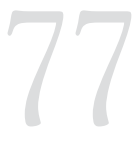

EL EQUILIBRIO

ECONÓMICO EN LOS CONTRATOS

ADMINISTRATIVOS

THE ECONOMIC

BALANCE IN

ADMINISTRATIVE

CONTRACTS

[...] en el sub-lite, el demandante no demostró que las utilidades obtenidas fueron muy inferiores a las programadas cuando contrató, con grave detrimento de sus intereses, como tampoco se acreditó cuál es la real situación económica del contrato en cuanto a cargas y beneficios después de los descuentos que por concepto de contribución especial, le fueron practicados en algunos pagos. En tales condiciones, se evidencia la falta de prueba de la excepcional onerosidad que supuestamente representó el cumplimiento de la medida estatal frente a las condiciones generales del contrato pactadas al momento de su celebración, es decir que no se acreditó en realidad, el elemento indispensable para condenar a la entidad demandada, esto es, el rompimiento del equilibrio económico del contrato, toda vez que no hay manera de establecer, frente al total de gastos que implicó la ejecución del contrato, cuál fue el resultado en materia de utilidades o pérdidas del contratista, para deducir a partir de estos datos, la real condición de la ecuación económica del negocio jurídico y si la misma mantenía el equilibrio creado al momento de contratar, o si este verdaderamente se afectó de manera grave" (mis subrayados $)^{57}$.

\section{INSTRUMENTOS JURÍDICOS PARA HACER EFECTIVO EL DERECHO AL RESTABLECIMIENTO DEL EQUILIBRIO ECONÓMICO DEL CONTRATO}

Los ordenamientos jurídicos de los diversos países que aplican el principio del equilibrio económico en los contratos administrativos ofrecen diferentes instrumentos o mecanismos jurídicos para que pueda hacerse efectivo el derecho de las partes de un contrato administrativo

55 Consejo de Estado, Sala de lo Contencioso Administrativo, sección tercera: sentencia del 4 de septiembre de 2003, expediente 1989-05337 (10883).

56 Consejo de Estado, Sala de lo Contencioso Administrativo, sección tercera: sentencia del 11 de noviembre de 2003, expediente 1998-15988 (19.478).

57 Consejo de Estado, Sala de lo Contencioso Administrativo, sección tercera: sentencia del 18 de septiembre de 2003, expediente 1996-05631 (15.119). 
al mantenimiento de la reciprocidad entre las prestaciones pactadas. Estos diversos instrumentos, aunque con matices en cada caso concreto, se pueden clasificar en tres grupos: los instrumentos contractuales, los instrumentos de reclamación directa y los instrumentos judiciales.

\section{V.1. Los instrumentos contractuales}

Las partes en un contrato administrativo, al prever la posibilidad de que acaezcan hechos o circunstancias que puedan alterar las condiciones inicialmente pactadas, tienen la posibilidad de estipular diversas clases de cláusulas que neutralicen o mitiguen los efectos de tales hechos o circunstancias. A continuación, las explicamos ${ }^{58}$.

En primer lugar, las partes pueden pactar una cláusula de reajuste de precios conforme a la cual se fijan las variables que se consideren más relevantes en la ejecución contractual, como pueden ser, por ejemplo, el valor de los materiales y el índice de variación de precios. A partir de ella, se elabora una fórmula para ser aplicada en cada uno de los pagos que deban realizarse durante la ejecución del contrato. La aplicación de la fórmula pactada supone que cada uno de los pagos se hace en conformidad con los valores reales del mercado, de tal manera que se mantiene materialmente idéntico el valor de las prestaciones. Estas fórmulas de reajuste son, en general, muy beneficiosas para ambas partes, ya que, como el valor de los pagos se ajusta a los precios reales del mercado, ni la administración paga un precio superior al que debía pagar ni el contratista sufre una disminución en la remuneración prevista.

Ahora bien, no obstante que la cláusula de reajuste es el pacto más común para neutralizar o mitigar los efectos de los hechos perturbadores de la economía del contrato, existen otras clases de pactos que permiten llegar a idéntica finalidad. En este orden de ideas, es posible pactar cláusulas de renegociación o hardship — creadas por la costumbre comercial internacional-, las cuales hacen referencia al pacto que hacen las partes en el sentido de que, una vez acaezcan hechos que alteren el equilibrio económico del contrato, ellas tienen el deber contractual de ponerse de acuerdo para revisar el negocio en todos sus aspectos - no simplemente en cuanto al precio-, y regenociar, en consecuencia, las prestaciones debidas por el contratista y el precio que deberá pagar la administración por ellas. Al margen de las aparentes ventajas de la estipulación, esta ha sido objeto de críticas por su imprecisión y porque impide el ejercicio de los poderes de dirección y control del contrato por parte de la administración ${ }^{59}$.

58 Sobre las diversas clases de mecanismos convencionales, véase Ariño Ortíz, Gaspar. Teoría del equivalente económico en los contratos administrativos. Ob. cit., pp. 346 y siguientes y Palacio Hincapié, Juan Ángel. La contratación de las entidades estatales. Quinta edición. Medellín: Librería Jurídica Sánchez R., 2005, pp. 364 y siguientes.

59 En relación con esta cláusula, véase Ghestin, Jacques y Marc Billau. El precio en los contratos de larga duración. Buenos Aires: Zavalia, 1994, pp. 184 y siguientes. 


\section{V.2. Los instrumentos de reclamación directa}

Estos instrumentos se refieren, fundamentalmente, a la posibilidad $\mathrm{u}$ obligación que tiene el cocontratante afectado de pedir directamente a su cocontratante —administración pública o contratista, según el caso- que se reconozca que una determinada alteración en las condiciones en que se pactaron las obligaciones contractuales le genera mayores costos que no está en el deber jurídico de soportar y que, por lo tanto, le deben ser compensados. Se trata, entonces, de la búsqueda de un arreglo directo entre las partes.

En Colombia, estos mecanismos se encuentran consagrados en el artículo 68 de la ley 80 de 1993, conforme al cual las entidades estatales contratantes y los contratistas tienen el deber de procurar solucionar en forma ágil, rápida y directa todas las diferencias y discrepancias surgidas de la actividad contractual, procesos en los cuales pueden emplear mecanismos como la transacción, la conciliación y la amigable composición.

Según lo tiene entendido la jurisprudencia constitucional colombiana, en virtud de los principios de economía y de garantía del patrimonio de los particulares "el principio del arreglo directo constituye uno de los pilares fundamentales bajo los cuales se edifica el Estatuto de la Contratación Estatal o Administrativa. Su propósito consiste en someter las controversias o divergencias que se presentan en la ejecución y desarrollo de la actividad contractual a la solución de manera rápida, inmediata y directa de las partes" ${ }^{\prime \prime}$.

La primera situación que se debe tener en cuenta es aquella en la cual el cocontratante de la administración considera que en la ejecución de un contrato administrativo ha incurrido en mayores costos respecto de los pactados, de acuerdo con las condiciones en que se celebró el contrato o se presentó la propuesta — según sea el caso-. En este evento, este tiene no solo el derecho, sino el deber, de acudir directamente a la administración para reclamarle esos mayores costos cuyos hechos generadores, en todo caso, deben cumplir con las condiciones anotadas en el punto IV de este escrito. Ante una reclamación de esta naturaleza, la administración, en caso de encontrar que se cumplen los requisitos legales para la configuración de la ruptura del equilibrio económico del contrato administrativo, debe optar por su reconocimiento y ordenar el pago directo de esos mayores valores. Inclusive la ley 80 de 1993, en su artículo 25.14, prevé que las entidades públicas tienen el deber de incluir en sus presupuestos anuales una apropiación global destinada a cubrir los costos imprevistos ocasionados por los retardos en los pagos, así como los que se originen en la revisión de los precios pactados por

\section{EL EQUILIBRIO \\ ECONÓMICO EN LOS CONTRATOS ADMINISTRATIVOS \\ THE ECONOMIC \\ BALANCE IN ADMINISTRATIVE CONTRACTS}


razón de los cambios o alteraciones en las condiciones iniciales de los contratos por ellas celebrados.

La respuesta de la administración pública a la reclamación presentada por su cocontratante es, obviamente, un acto administrativo, en la medida en que contiene su manifestación de voluntad en el sentido de negar la reclamación, aceptarla parcialmente o aceptarla completamente — a diferencia del primero, en los últimos dos casos se genera una orden directa de pago- Como se trata de un acto administrativo, en caso de que el cocontratante considere que la respuesta de la administración a su reclamación no fue satisfactoria, tendrá derecho a ejercer los recursos administrativos o en vía gubernativa, los cuales, por mandato del artículo 77 de la ley 80 de 1993, se limitarán al recurso de reposición. No obstante, el eventual cuestionamiento judicial de estos actos administrativos no se realiza a través de las acciones judiciales propias de los actos administrativos, sino a través de la llamada en Colombia "acción de controversias contractuales", cuyo término de caducidad es, por regla general, de dos años — contados a partir de la fecha de vencimiento de la obligación legal de liquidar el contrato respectivo-.

Finalmente, en cuanto a la reclamación presentada por el cocontratante de la administración, vale la pena aclarar que, no obstante que el ordenamiento jurídico colombiano prevé la existencia de un silencio administrativo positivo respecto de las peticiones presentadas por el cocontratante de la administración, la jurisprudencia contencioso-administrativa ha aclarado que tal silencio no es aplicable cuando se trata de reclamaciones económicas ${ }^{61}$, por lo cual, no puede más que afirmarse que el reconocimiento en vía administrativa de la ruptura del equilibrio económico del contrato requiere de manifestación expresa de la entidad estatal contratante.

En el caso contrario, es decir, cuando la administración es quien considera que la diferencia de costos se ha presentado en su favor, y hace la petición a su contratista, este tiene la posibilidad de reconocer la ruptura del equilibrio y proceder a aceptar la reducción del valor de la contraprestación por la ejecución de las contraprestaciones pactadas, o bien puede negarse a ello. En el segundo caso, la administración tendrá la posibilidad de iniciar la denominada acción de controversias contractuales con la pretensión de lograr el restablecimiento del equilibrio económico del contrato. 
No obstante la posibilidad que tienen las partes de realizar un reconocimiento directo y unilateral de la ruptura del equilibrio económico del contrato en perjuicio de su cocontratante, la manera de instrumentalizar un acuerdo de las características descritas también puede adquirir otras facetas: puede suscribirse una adición de contrato - en la cual se modifica el valor de las prestaciones_ o puede suscribirse un negocio jurídico de transacción o suscribirse una conciliación, con la misma finalidad.

\section{V.3. Los instrumentos judiciales}

El tercer grupo de mecanismos para hacer efectivo el derecho al mantenimiento de la reciprocidad en las prestaciones pactadas - es decir, el derecho al mantenimiento del equilibrio económico del contratoencuentra sustento en el derecho constitucional fundamental de acceso a la administración de justicia o de tutela judicial efectiva y se instrumentaliza en una decisión de la autoridad judicial competente. Así, en caso de que una de las partes considere que existe una ruptura en el equilibrio económico del contrato y no haya sido posible lograr un arreglo directo entre ellas, dicha parte puede acudir al juez del contrato para que declare la ocurrencia de tal ruptura y condene al cocontratante obligado a tomar las medidas necesarias para lograr el restablecimiento - es decir, para que ordene una compensación o una indemnización de los perjuicios sufridos como consecuencia de la ruptura, o una revisión del contrato para ajustar las prestaciones a la realidad fáctica-

Estos mecanismos también encuentran consagración expresa en el ordenamiento jurídico colombiano, tanto en el estatuto de contratación de la administración pública como en el Código Contencioso Administrativo. En efecto, los artículos 70 a 75 de la ley 80 de 1993 prevén la solución judicial de las controversias surgidas con ocasión de la actividad contractual, ya sea por un Tribunal de Arbitramento — en el evento en que las partes hayan suscrito un pacto arbitral—o por la jurisdicción de lo contencioso administrativo, quien es el juez natural de los contratos de la administración pública en Colombia.

En concordancia con las normas del estatuto de contratación de la administración, el Código Contencioso Administrativo, en su artículo 87, prevé la existencia de una acción contencioso-administrativa denominada acción de controversias contractuales. En virtud de esta acción, cualquiera de las partes de un contrato administrativo puede solicitar al juez del contrato que se hagan toda clase de declaraciones, incluidas la de incumplimiento y la de ruptura del equilibrio económico del contrato, con las consecuentes condenas a que haya lugar. Adicionalmente, el mismo código prevé el término dentro del cual debe ejercerse la acción judicial —que es, por regla general, de dos años

EL EQUILIBRIO

ECONÓMICO EN LOS CONTRATOS ADMINISTRATIVOS

THE ECONOMIC

BALANCE IN ADMINISTRATIVE CONTRACTS 
contados a partir de la fecha de vencimiento de la obligación legal de liquidar el contrato respectivo-, así como los demás aspectos formales indispensables para el debido ejercicio del derecho de acción de las partes del contrato administrativo ${ }^{62}$.

\section{CAUSALES ESPECÍFICAS QUE DAN LUGAR A LA RUPTURA DEL EQUILIBRIO ECONÓMICO EN LOS CONTRATOS ADMINISTRATIVOS}

El equilibrio económico del contrato puede alterarse por diversas razones o causales, sobre las cuales no existe uniformidad ni acuerdo en la doctrina, no obstante lo cual, como pasamos a exponerlo, es posible establecer una clasificación que comprenda las diferentes situaciones que pueden dar lugar a esa ruptura.

$\mathrm{Al}$ respecto, debe señalarse que la importancia de realizar un análisis detallado y específico de las mismas radica no solo en su concepto, origen, evolución y justificación, sino, especialmente, en las particularidades que cada una presenta en relación con las condiciones que debe comportar la alteración de las circunstancias existentes al momento de contratar y en la diversidad de efectos jurídicos que su aplicación genera.

Para comprender la diversidad de tesis expuestas, debemos comenzar por un primer sector de la doctrina que clasifica las casuales según la clase de álea que afecte la ejecución del contrato: de una parte, los áleas administrativos, que son aquellos originados en la acción unilateral de la administración, ya sea por la expedición de un acto general (factum principis o fait du prince) o de un acto contractual (potestas variandi o ius variandi); de otra parte, puede tratarse de áleas empresariales, que son los riesgos internos del negocio, entre ellos los errores de cálculo (error calculi), los daños o destrucción de las cosas (periculum rei) o las dificultades materiales de ejecución del proyecto (sujetions materiales imprevues); y, finalmente, los áleas económicos, que se refieren a las alteraciones en las condiciones económicas externas que hacen más gravosa la ejecución del contrato (teoría de la imprevisión) ${ }^{63}$.

Dentro del marco anterior, otros doctrinantes han simplificado la presentación de los eventos que generan el rompimiento de la equivalencia económica en las prestaciones, al identificar, como causales de ruptura del equilibrio económico del contrato, únicamente el incumplimiento, la potestas variandi, el hecho del príncipe, la teoría de la imprevisión y

62 Para extenderse sobre la solución judicial de las controversias contractuales, puede consultarse González Rodríguez, Miguel. El contencioso contractual. Pereira: Universidad Libre, 2000; así como también Betancur Jaramillo, Carlos. Derecho procesal administrativo. Sexta edición. Medellín: Señal Editora, 2002, pp. 503 y siguientes.

63 Esta clasificación es presentada por Gaspar Ariño Ortíz en las páginas 7 y 8 de su libro Teoría del equivalente económico en los contratos administrativos, ob. cit. 
las sujeciones materiales imprevistas ${ }^{64}$, sin incluir —expresamente- los errores de cálculo y los daños o destrucción de las cosas.

Por su parte, un sector de la doctrina argentina ha señalado que los factores que alteran el equilibrio económico del contrato son el incumplimiento y las teorías del hecho del príncipe y la imprevisión ${ }^{65}$. A su vez, la doctrina francesa ha limitado aún más la presentación de los eventos que dan lugar a la ruptura del equilibrio económico del contrato, al hacer referencia solamente a las teorías del hecho del príncipe, de la imprevisión y de las sujeciones materiales imprevistas ${ }^{66}$.

La jurisprudencia colombiana, sin incluir el incumplimiento ni los errores de cálculo y la destrucción de las cosas, ha dicho de manera reiterada que "el equilibrio económico del contrato puede verse alterado durante su ejecución, por las siguientes causas: $1^{\circ}$ ) por actos o hechos de la administración contratante; $2^{\circ}$ ) por actos de la administración como Estado, y $3^{\circ}$ ) por factores exógenos a las partes del negocio jurídico" ${ }^{16}$. Estas causales de ruptura del equilibrio económico del contrato señaladas por la jurisprudencia colombiana corresponden, en términos generales, respecto de las categorías elaboradas por la doctrina, a la potestas variandi (la identificada en el punto primero), al hecho del príncipe (la del punto segundo), y a la teoría de la imprevisión y las sujeciones materiales imprevistas (la del punto tercero).

Frente a esa falta de uniformidad en las clasificaciones de las causales que dan lugar a la ruptura del equilibrio económico del contrato, aparece la inquietud sobre cuáles de ellas, efectivamente, forman parte de la teoría del equilibrio económico del contrato. $\mathrm{Al}$ respecto, y a nuestro juicio - como a continuación lo sustentaremos-, estas se limitan a la potestas variandi, el hecho del príncipe, la teoría de la imprevisión y el incumplimiento del contrato. Esta clasificación excluye las sujeciones materiales imprevistas, los errores de cálculo (error calculi) y la destrucción de las cosas (periculum rei), por cuanto dichas circunstancias no generan en estricto sentido la ruptura del equilibrio económico del contrato o, en realidad, forman parte de otra de las causales indicadas.

En efecto, las sujeciones materiales imprevistas forman en realidad parte de la teoría de la imprevisión. Es así como no se trata de una teoría con fundamentos, condiciones de existencia y efectos propios, sino que

64 Véase Dávila Vinueza, Luis Guillermo. Régimen jurídico de la contratación estatal. Segunda edición. Bogotá: Legis Editores, 2003, pp. 496 y siguientes.

65 Véase Escola, Héctor Jorge. Tratado integral de los contratos administrativos. Ob. cit., tomo I, número 104; y Marienhoff, Miguel S. Tratado de Derecho administrativo. Ob. cit., tomo III-A, números 761 y siguientes.

66 Véase a De Laubadère, André, Franck Moderne y Delvolvé. Traité des contrats administratifs. Ob. cit., volumen II, números 1273 y siguientes; y Richer, Laurent. Droit des contrats administratifs. Ob. cit., números 351 y siguientes.

67 Consejo de Estado, Sala de lo Contencioso Administrativo, sección tercera: sentencia del 2 septiembre de 2004, expediente 1996-04029 (14.578).

\section{EL EQUILIBRIO \\ ECONÓMICO EN LOS CONTRATOS ADMINISTRATIVOS \\ THE ECONOMIC BALANCE IN ADMINISTRATIVE CONTRACTS}


estamos apenas frente a la aplicación de la teoría de la imprevisión a unos hechos o situaciones concretos, relacionados con las dificultades materiales que pueden presentarse en la ejecución de obras públicas, para cuya aplicación práctica se deben tener en cuenta los mismos fundamentos y requisitos de la teoría de la imprevisión, lo cual impide que sea considerada como una causal autónoma de ruptura del equilibrio económico del contrato.

De otra parte, como parece aceptarlo el propio Gaspar Ariño, a pesar de que tanto el periculum rei como el error calculi pueden incluirse dentro de los áleas que afectan la ejecución del contrato administrativo, dichas circunstancias, en estricto sentido, no dan lugar a una ruptura del equilibrio económico del mismo ${ }^{68}$.

En particular, el periculum rei no conlleva la aplicación directa del principio del equilibrio económico del contrato, sino que supone la asunción de los mayores costos por la parte que asumió el riesgo cuya consolidación dio lugar a la mayor onerosidad en la ejecución del contrato, de tal manera que su aplicación se basa en figuras distintas al principio que es objeto de estudio en este trabajo, como es la teoría de los riesgos de la cosa o, incluso, el caso fortuito o fuerza mayor.

A su vez, respecto del error calculi ocurre algo similar que en el caso del periculum rei, toda vez que dicha figura no se basa en el principio del equilibrio económico del contrato, sino en otras figuras jurídicas, como la responsabilidad por el hecho propio o la culpa de la víctima, las cuales no dan lugar al derecho al restablecimiento del equilibrio económico por ser directamente imputables al afectado, quien será el que deberá asumir los mayores costos que se derivan del error que cometió en la formación del contrato o en su ejecución.

$\mathrm{Al}$ respecto, debe hacerse notar que, a nuestro juicio, la exclusión del error calculi como causal de ruptura del equilibrio económico del contrato en los anteriores términos simplemente se limita a la perspectiva del caso en el cual quien comete el error es la misma parte perjudicada, pero no analiza la posibilidad de que sea la otra parte del contrato quien resulte perjudicada. En este caso, sí podría hablarse —eventualmentede una afectación en la equivalencia de las prestaciones, la cual podría dar lugar al restablecimiento del equilibrio económico. De todos modos, el sustento jurídico para la aplicación del principio del equilibrio económico del contrato sería alguna otra de las causales que dan lugar a su ruptura — como el incumplimiento-, de tal manera que, desde esta perspectiva, el error calculi debe ser entendido como una forma específica de incumplimiento del contrato, pues comparte las mismas

68 Véase Ariño Ortíz, Gaspar. Teoría del equivalente económico en los contratos administrativos. Ob. cit., pp. 133 y siguientes y 146 y siguientes. 
condiciones y efectos que dicha forma de ruptura con respecto de la ecuación contractual.

Finalmente, hemos decidido incluir al incumplimiento - a pesar de la discusión existente sobre su configuración como causal de ruptura del equilibrio económico del contrato-, puesto que el acreedor insatisfecho tendrá el derecho al restablecimiento de la equivalencia de las prestaciones pactadas, mediante el pago de los perjuicios sufridos, siempre que se configuren los requisitos especiales de la responsabilidad contractual a pesar de que estos últimos sean distintos de los de los demás eventos de ruptura del equilibrio económico del contrato-. Lo anterior permite afirmar que la figura de la ruptura del equilibrio económico de los contratos administrativos puede tener dos acepciones diferentes: una restringida, que comprende únicamente aquellas situaciones en las cuales se produce una alteración de la equivalencia de las prestaciones como consecuencia de las teorías de la potestas variandi, el hecho del príncipe y la imprevisión; y una amplia, que incluye toda situación en la cual pueda verse alterada la equivalencia material de las prestaciones a cargo de las partes, es decir, que comprende tanto la alteración producida por la aplicación de las teorías mencionadas, como la alteración que obedece al incumplimiento de las obligaciones contractuales.

En todo caso, puede afirmarse que la aplicación del principio del equilibrio económico en el contrato administrativo —originada específicamente en cada una de esas causales o teorías indicadas, que han sido denominadas por otro sector de la doctrina como "técnicas de garantía del equilibrio financiero del contrato" ${ }^{19}$ - debe hacerse dentro del marco de las condiciones o criterios generales que expusimos en este capítulo.

Sin embargo, debe señalarse que la importancia de realizar un análisis detallado y específico de las causales de ruptura del equilibrio económico del contrato radica no solo en las particularidades que cada una ofrece en relación con las condiciones que debe comportar la alteración de las circunstancias tenidas en cuenta al momento de contratar, sino también con la diversidad de efectos que su aplicación supone ${ }^{70}$.

\section{CONCLUSIONES}

Como resultado de los análisis y comentarios expresados en las páginas anteriores, podemos extraer las siguientes conclusiones:

EL EQUILIBRIO ECONÓMICO EN LOS CONTRATOS ADMINISTRATIVOS

THE ECONOMIC BALANCE IN ADMINISTRATIVE CONTRACTS 
1. El equilibrio económico es un principio de los contratos administrativos que consiste en que las prestaciones que las partes pactan, de acuerdo con las condiciones tomadas en consideración al momento de presentar la propuesta o celebrar el contrato, deben permanecer equivalentes hasta su término, de tal manera que, si se rompe esa equivalencia, nace para el afectado el derecho a una compensación pecuniaria que la restablezca.

2. La aplicación sistemática de este principio es un aporte del Derecho administrativo a la teoría general de los contratos, ya que ha venido a limitar la aplicación del principio de riesgo y ventura - tradicional y propio de la institución jurídica de los contratos-, de acuerdo con el cual, en aplicación estricta de los conceptos de autonomía de la voluntad y del contrato como ley para las partes, el cambio en las condiciones contractuales no permite la revisión del mismo ni la condena a compensación o indemnización alguna.

3. La aplicación de este principio en los contratos de la administración encuentra su origen en Francia a comienzos del siglo XX, y desde entonces ha sido adoptado por los diversos países que aplican la teoría del contrato administrativo. En Colombia, la aplicación de este principio se remonta a la década de los setenta del siglo XX.

4. El principio del equilibrio económico de los contratos administrativos encuentra su justificación en las necesidades de prestación continua y eficiente del servicio público, así como también funciona a modo de contrapartida a las prerrogativas del poder público de las que goza la administración en un contrato administrativo, y, a su vez, se justifica en los principios constitucionales del deber general que tiene el Estado de reparar los daños antijurídicos generados por sus actuaciones, la obligación de mantener la igualdad ante las cargas públicas, la garantía del patrimonio de los particulares, y el deber de garantizar la vida, honra y bienes de las personas —en la justicia contractual, y en la conmutatividad del contrato administrativo-.

5. A pesar de la aparente generalidad del principio, no toda alteración de las condiciones previstas al momento de presentación de la propuesta o de la celebración del contrato conlleva su aplicación, pues para que ella sea procedente se requiere que la alteración se haya producido por acontecimientos que no sean imputables a la parte que reclama el restablecimiento, que los acontecimientos sean posteriores a la presentación de la propuesta o la celebración del contrato, que la alteración supere el álea normal propia de los contratos sinalagmáticos, y que la afectación de las condiciones económicas del contrato sea grave y anormal. 
6. Los regímenes jurídicos de los diferentes países que reconocen este principio consagran instrumentos para su efectiva aplicación, tanto contractuales y de solución directa entre las partes, como judiciales, los cuales, obviamente, presentan las características propias del régimen de cada país.

7. No obstante la falta de uniformidad en las clasificaciones de las causales que dan lugar a la ruptura del equilibrio económico del contrato, elaboradas por la doctrina y la jurisprudencia, consideramos que ellas se concretan en la potestas variandi, el hecho del príncipe, la teoría de la imprevisión y el incumplimiento del contrato.

EL EQUILIBRIO

ECONÓMICO EN

LOS CONTRATOS

ADMINISTRATIVOS

THE ECONOMIC

BALANCE IN

ADMINISTRATIVE

CONTRACTS 